properties of the enzyme preparations and of the depolymerase have been investigated and results recorded. The differences between the pectic enzymes of $B$. aroideae and those from other sources, and the possible identity of depolymerase, polygalacturonase and protopectinase, are discussed.

\section{Symbiotic Systems for Nitrogen Fixation}

G. Bond and G. D. Scott have been able to demonstrate, by using nitrogen-15, the occurrence of fixation of elemental nitrogen in the lichens Collema granosum and Leptogium lichenoides, in both of which Nostoc is present as the algal component (Ann. Bot., N.S., 19, $65 ; 1955)$. A similar result has been demonstrated in the liverwort Blasia pusilla in which Nostoc is present in thallus cavities. The indications are that Nostoc is the agent responsible for the nitrogen fixation. In the same investigation, no evidence was obtained of nitrogen fixation on the mycorrhizal roots of intact plants of Calluna vulgaris or of Pinus sylvestris, both of which, but especially the former, have been held by previous investigators to be capable of nitrogen fixation.

\section{Zoological Nomenclature}

Notice is hereby given that, as from August 28, 1955, the International Commission on Zoological Nomenclature will start to vote on the following cases involving the possible use of the plenary powers for the purposes specified against each entry. Full particulars of these cases were published on February 28, 1955, in Parts 3 and 4 of Vol. 11 of the Bulletin of Zoological Nomenclature. (1) Entomobrya Rondani, 1861 (Cl. Insecta, Order Collembola), validation of ; (2) Iphis Leach, 1817 (Cl. Crustacea, Order Decapoda), validation of (correction of error in Opinion 73) ; (3) Homalaspis Milne Edwards (A.), 1863 (Cl. Crustacea, Order Decapoda), validation of (correction of error in Opinion 85) ; (4) Monticulipora d'Orbigny, 1849 (Cl. Bryozoa), designation of type species for ; (5) obscura Berezowsky and Bianchi, 1891 (Larvivora) (Cl. Aves), validation of ; (6) bei Ridgway, 1874 (Eremophila alpestris var.), suppression of; (7) dingo Meyer, 1793 (Canis) (Cl. Mammalia), validation of, as the name for the dingo ; (8) Bombina Oken, 1816 (Cl. Amphibia, Order Anura), conservation of ; (9) Scolopendra Linnæus, 1758 (Cl. Myriapoda), designation of type species for. Proposals are also made for the adoption of two 'Declarations' : (a) clarifying Rule $(g)$ of Article 30, relating to the selection of the type species, in cases where a species has two or more names objectively synonymous with one another; (b) regarding the specific name to be adopted for the type species of a genus in cases where that species possesses two or more objectively synonymous such names. Comments should be sent as soon as possible to Francis Hemming, secretary to the Commission, 28 Park Village East, Regent's Park, London, N.W.1.

\section{Biochemical Periodicals in Poland}

THE successful reorganization of teaching and research activities in Polish biochemistry is well illustrated by the publication of no fewer than three new journals sponsored by the Polish Academy of Sciences in Warsaw, and devoted largely to biochemistry. Postepy Biochemii (Progress in Biochemistry) is edited by Prof. J. Heller, and consists of review-articles based on symposia organized periodically by the Biochemical Committee of the Academy. The latest issue (No. 2) reports on two such symposia, one on clinical biochemistry, with contributions by W. Mozolowski and Z. Stolzmann, among others; the other on plant biochemistry and chemical mycology. Acta Biochimica Polonica is a quarterly, devoted entirely to original papers, written in Polish, but with extensive summaries in both Russian and English. Volume 1 includes among its thirteen papers several original contributions on blood biochemistry (including one by Skarzynski and another one by Mozolowski) as well as some extensive analytical studies on purine bases by Dmochowski. Bulletin de l'Académie Polonaise des Sciences, Classe Deuxieme, covers the whole field of biological and medical sciences and consists of papers communicated by members of the Academy. A recent issue (Vol. 2, No. 2) contains ten papers (all in English), of which three are biochemical, one by Galos and Ostrowski on the electrophoretic separation of carbohydrates, another by Zakrzewski et al. on physicochemical properties of dextran, and a third by Shugar and Syruczek on lysozyme, mainly on the kinetics of its inactivation by heat.

\section{Van de Graaff Generator at the Weizmann Institute} of Science, Rehovoth

A 3-MV. Van de Graaff positive-ion accelerator is being constructed specially for the Weizmann Institute of Science, Rehovoth, Israel, by the High Voltage Engineering Corporation of Cambridge, Mass., and, when installed, will be used at the Institute for studying nuclear reactions produced by the bombardment of the nuclei with high-energy protons. Dr. Gvirol Goldring, of the Weizmann Institute's Department of Nuclear Physics, is going to the United States, where he will take part in the construction of the Van de Graaff generator and be responsible later for its assembly, installation and operation at Rehovoth. He will spend some time at the Massachusetts Institute of Technology making himself familiar with the details of a similar generator already installed there. The new generator is due to be completed in the United States in December 1956 and to be installed in the new building of the Nuclear Physics Department at the Weizmann Institute in May 1957. Work on the building is scheduled to begin later this year as part of the Yad Chaim Weizmann programme of scientific and cultural development. On his way to the United States, Dr. Goldring, who is twenty-seven years old, is spending a month in France at the University of Strasbourg, where he has been invited by the Physics Department there to assist in drawing up an advanced programme connected with the Van de Graaff accelerator recently acquired by it.

\section{Wool Textile Research Conference in Australia}

A NUMBER of scientific workers of international reputation in wool research and related fields of study have been invited to attend a research conference on wool textiles, to be held in Australia during August-September under the auspices of the Commonwealth Scientific and Industrial Research Organization. Besides giving them the opportunity to discuss the latest developments in their particular topics, the conference will also enable members to see the advances that have been made in Australian research laboratories and to make contacts with Australian research workers. The members will be able to visit the C.S.I.R.O. wool textile research laboratories, which are situated in three of the principal Australian wool-manufacturing centres and comprise a bio- 